\title{
PERANCANGAN KONSTRUKSI PADA SEGWAY
}

\author{
Alvin Soesilo ${ }^{1)}$, Agustinus Purna Irawan ${ }^{1)}$ dan Frans Jusuf Daywin ${ }^{2)}$ \\ ${ }^{1)}$ Program Studi Teknik Mesin, Fakultas Teknik Universitas Tarumanagara, Jakarta \\ 2) Teknik Pertanian Institut Pertanian Bogor, Bogor \\ e-mail: alvin_soesilo@yahoo.co.id
}

\begin{abstract}
Segway is the two wheeled personal transportation device which is light, strong, can balance themselves and used for short distance. On this segway design, performed modeling and construction load simulation with the help of Autodesk Inventor Professional 2012 software. On the loading simulation results, it was shown that segway's construction have good strength, so it is safe to be driven.
\end{abstract}

Keywords: segway, construction design, construction load simulation

\section{PENDAHULUAN}

Perkembangan teknologi kendaraan bermotor yang sangat pesat [1] menyebabkan peningkatan kebutuhan manusia terhadap sarana transportasi yang praktis, ramah lingkungan, dan dapat membantu aktifitas manusia sehari-hari. Untuk memenuhi kebutuhan tersebut, diciptakan kendaraan roda dua dengan penggerak berupa motor listrik yang dinamakan segway.

Perancangan konstruksi segway ini dititikberatkan pada perancangan konstruksi segway yang diperuntukan untuk kondisi jalan yang rata, tanpa lubang, tanjakan maupun turunan, penentuan material konstruksi yang digunakan, membuat desain dan menganalisa kekuatan konstruksi segway menggunakan software Autodesk Inventor.

Perancangan konstruksi merupakan salah satu bagian penting dalam merancang suatu kendaraan, dalam hal ini adalah segway. Konstruksi rangka kendaraan perlu dirancang dengan baik agar dapat menahan beban dan mendukung berbagai komponen yang terdapat pada kendaraan tersebut [2].

\section{METODE PERANCANGAN}

Metode yang digunakan dalam perancangan konstruksi pada segway ini adalah metode analitis untuk menganalisa kekuatan dari hasil desain menggunakan software.

Penelitian diawali dengan mengumpulkan informasi yang dibutuhkan tentang segway, terutama dalam perancangan konstruksi. Informasi dikumpulkan dari berbagai sumber, seperti internet, pustaka, dan penelitian lapangan. Pemodelan 3 dimensi dilakukan untuk kemudian dianalisa menggunakan software. Apabila pada analisa rancangan tidak terjadi tegangan yang melebihi tegangan ijin, maka rancangan aman dan proses dilanjutkan pada pembuatan komponen.

Komponen yang sudah dibuat dan disiapkan kemudian dirakit dan dilakukan pengujian, terutama pada kekuatan konstruksi sesuai dengan pembebanan pada kondisi aktual. Apabila konstruksi aman pada kondisi pembebanan aktual, maka perancangan telah selesai dan dapat ditarik kesimpulan sesuai dengan perancangan konstruksi yang dilakukan.

Pemodelan rancangan dalam bentuk 3 dimensi dan analisa kekuatan konstruksi dilakukan menggunakan software Autodesk Inventor. Analisa kekuatan konstruksi dilakukan untuk mengetahui dan mempelajari tegangan, regangan, dan pergeseran yang terjadi pada komponen yang dirancang.

Beberapa komponen pada segway yang dimodelkan menggunakan software Autodesk Inventor untuk kebutuhan konstruksi, yaitu struktur dasar, poros, dudukan poros, roda (pelek dan ban), klem aki, dan kemudi (steering). 


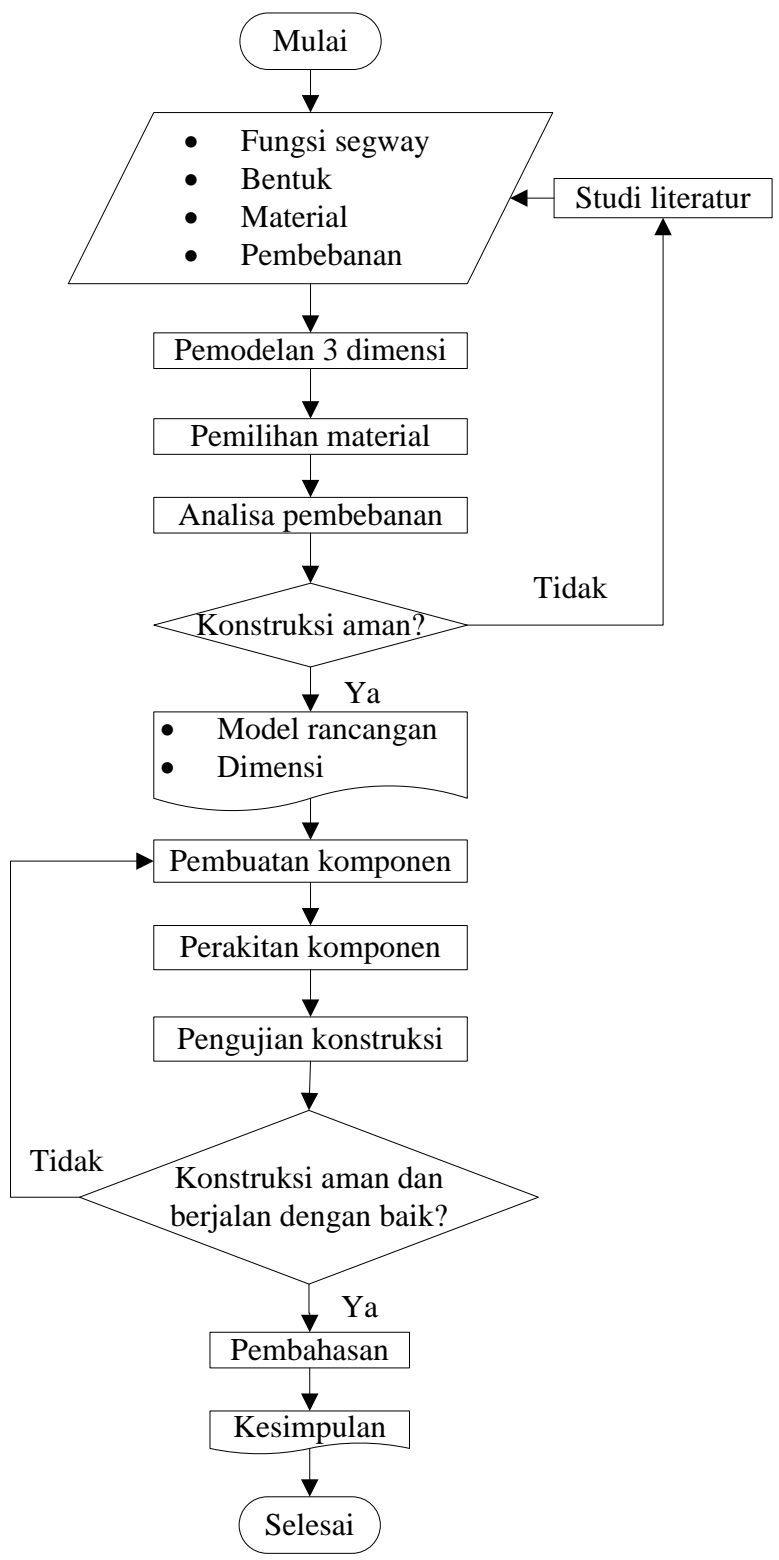

Gambar 1. Diagram alir penelitian

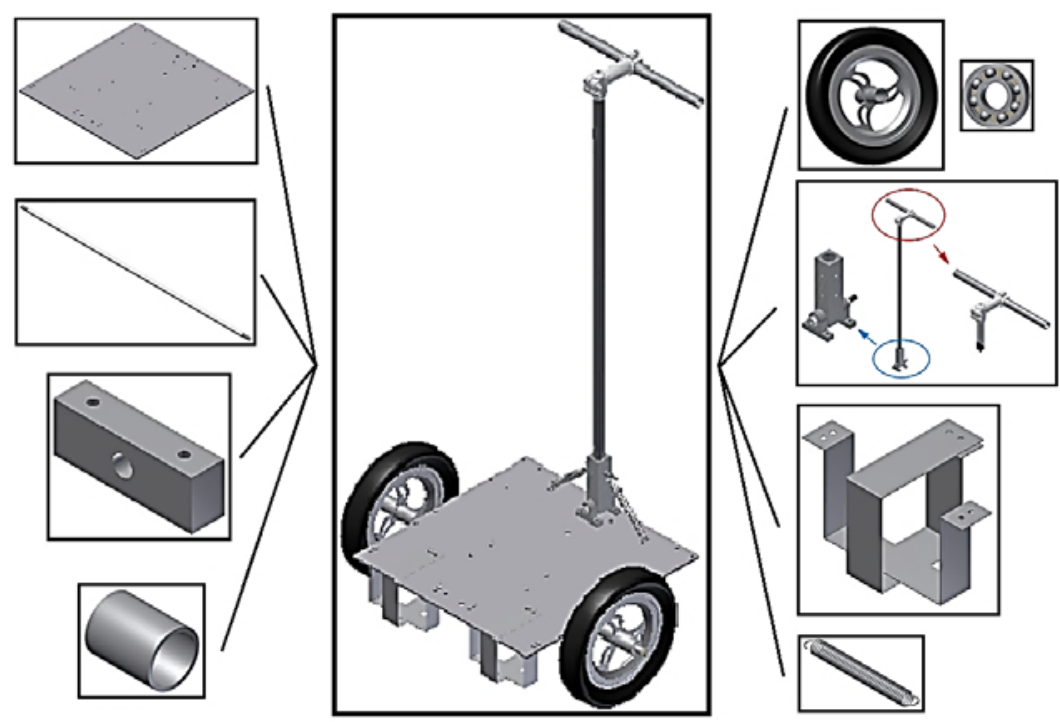

Gambar 2. Model segway dalam bentuk 3 dimensi 


\section{HASIL DAN PEMBAHASAN}

Simulasi pembebanan konstruksi segway dilakukan dengan memberikan beban sebesar masing-masing 0,022 MPa di kedua bagian pijakan kaki pengemudi pada struktur dasar dan 0,003 MPa pada klem aki.



Gambar 3. (a) Von mises stress konstruksi segway, (b) Displacement konstruksi segway

Simulasi pembebanan struktur dasar dilakukan dengan memberikan beban pada pijakan kaki tempat pengendara berdiri masing-masing sebesar 0,022 MPa karena berat yang ditumpu struktur dasar segway adalah $100 \mathrm{~kg}$, percepatan gravitasi $9,81 \mathrm{~m} / \mathrm{s}^{2}$ dan luas permukaan pijakan kaki pengendara diasumsikan sebesar $22.000 \mathrm{~mm}^{2}$. Struktur dasar ditumpu oleh 4 buah dudukan poros. Material yang digunakan pada struktur dasar adalah aluminium 6061 dengan ketebalan $6 \mathrm{~mm}$.

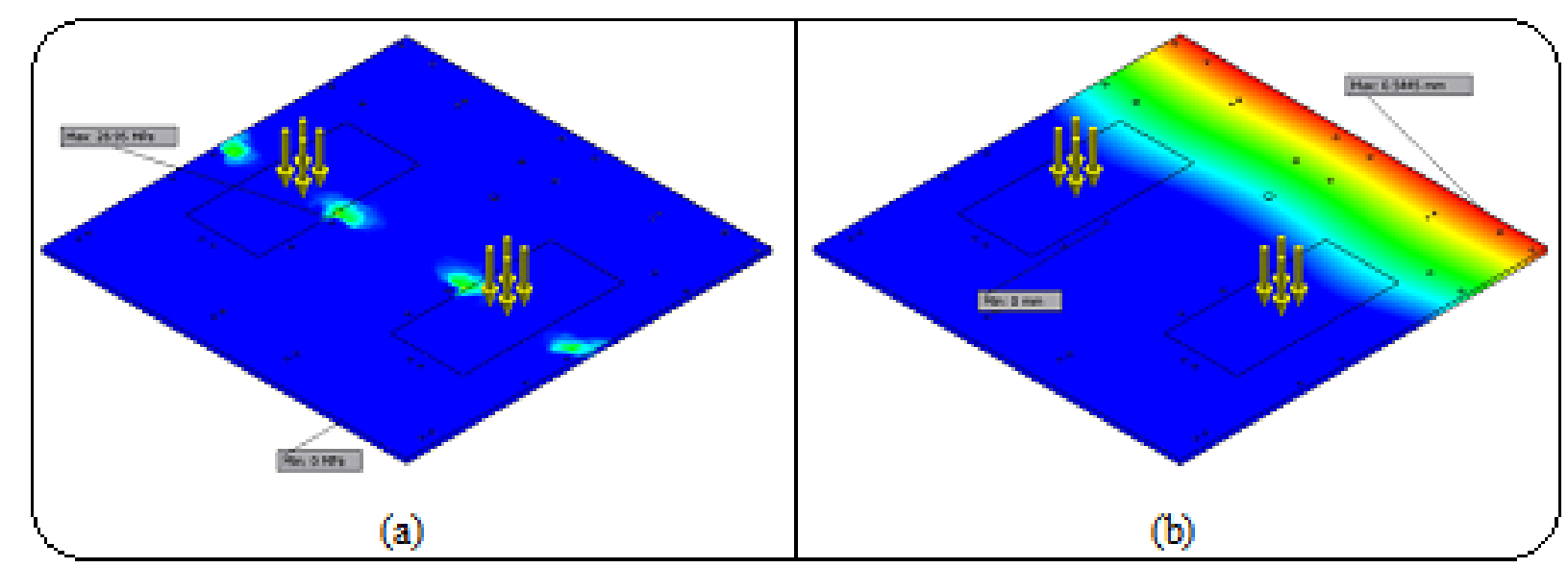

Gambar 4. (a) Von mises stress struktur dasar, (b) Displacement struktur dasar

Simulasi pembebanan pada poros segway dilakukan dengan memberikan beban sebesar 981 $\mathrm{N}$, karena berat yang ditumpu poros segway adalah $100 \mathrm{~kg}$ dan percepatan gravitasi $9,81 \mathrm{~m} / \mathrm{s}^{2}$. Poros ditumpu oleh 2 buah bantalan yang terhubung dengan pelek roda. Material yang digunakan untuk poros berupa mild steel-S45C [3] dengan diameter $12 \mathrm{~mm}$. 


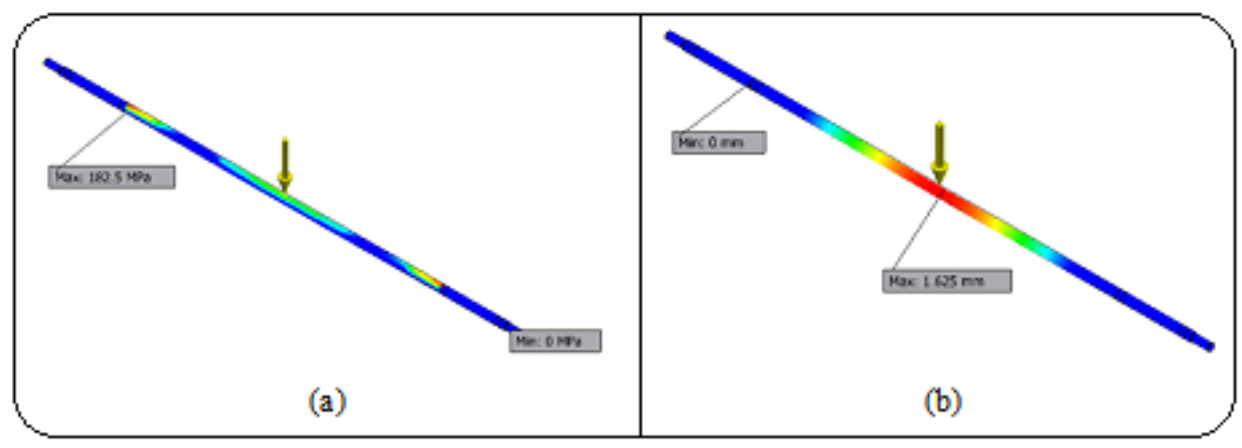

Gambar 5. (a) Von mises stress poros, (b) Displacement poros

Simulasi pembebanan pada dudukan poros dilakukan dengan memberikan beban bantalan (bearing load) sebesar 245,25 N, karena dudukan poros yang digunakan berjumlah 4, dan beban total yang ditumpu oleh seluruh dudukan poros sebesar $981 \mathrm{~N}$. Dudukan poros ditumpu oleh sambungan baut dan mur yang terhubung dengan struktur dasar. Material yang digunakan untuk dudukan poros adalah aluminium 6061.



Gambar 6. (a) Von mises stress dudukan poros, (b) Displacement dudukan poros

Simulasi pembebanan pada klem aki dilakukan dengan memberikan beban sebesar 0,003 MPa, karena berat aki sebesar $5 \mathrm{~kg}$, percepatan gravitasi 9,81 m/s $\mathrm{s}^{2}$ dan luas permukaan klem $8.840 \mathrm{~mm}^{2}$. Klem aki ditumpu oleh sambungan baut dan mur yang terhubung dengan struktur dasar. Material yang digunakan untuk klem aki adalah stainless steel $440 \mathrm{C}$ dengan tebal $1 \mathrm{~mm}$.



Gambar 7. (a) Von mises stress klem aki, (b) Displacement klem aki 
Simulasi pembebanan pada salah satu pelek dilakukan dengan memberikan beban bantalan (bearing load) sebesar 490,5 N, karena pelek yang digunakan berjumlah 2, dan beban total yang ditumpu kedua pelek sebesar 981 N. Pelek juga terkena beban torsi yang diasumsikan sebesar 220 Nmm. Pelek ditumpu oleh sisi luar pelek yang terhubung dengan ban. Material yang digunakan untuk pelek adalah aluminium 6061.

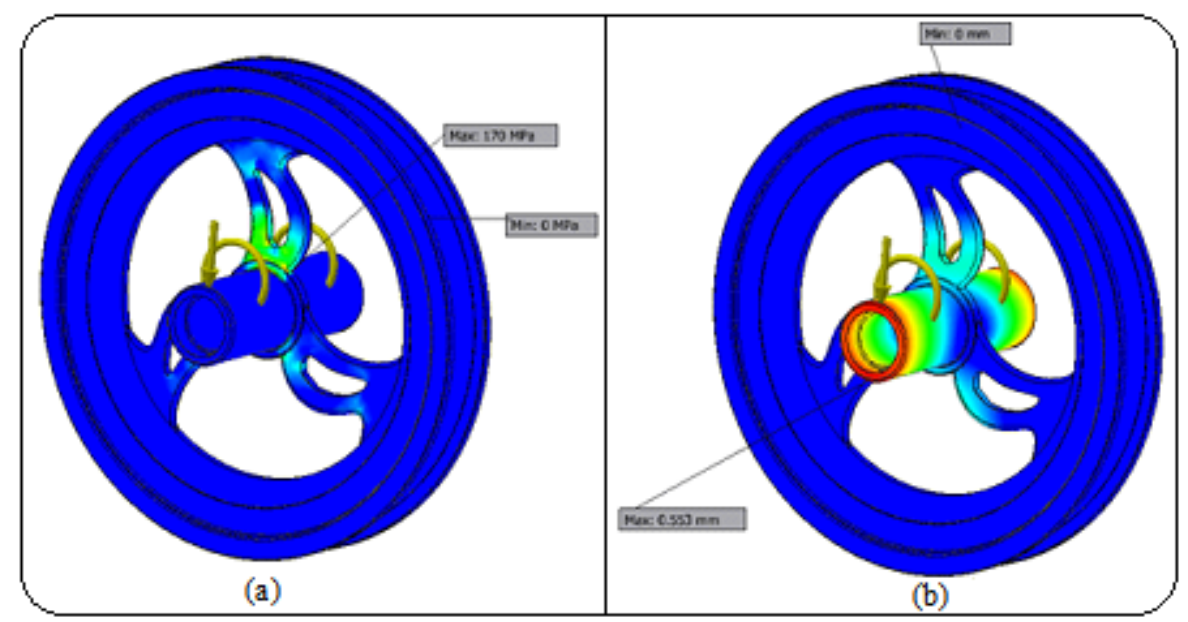

Gambar 8. (a) Von mises stress pelek, (b) Displacement pelek

Simulasi pembebanan pada steering dilakukan dengan memberikan beban sebesar 24,525 N pada kedua bagian setang kemudi. Steering ditumpu oleh sambungan baut dan mur yang terhubung dengan struktur dasar. Steering yang dirancang terdiri dari 4 komponen utama, yaitu dudukan batang kemudi, batang kemudi, kepala kemudi, dan setang kemudi. Material yang digunakan pada steering terdiri dari 2 jenis material, aluminium 6061 pada dudukan batang kemudi dan kepala kemudi, serta stainless steel 440C pada batang kemudi dan setang kemudi.



Gambar 9. (a) Von mises stress steering, (b) Displacement steering

Hasil simulasi pembebanan yang dilakukan menunjukkan bahwa seluruh komponen segway yang dirancang dan disimulasi dengan bantuan software aman dan layak digunakan karena memiliki nilai von mises stress maksimum lebih rendah dari tegangan ijin material yang digunakan. Hasil simulasi pembebanan ditampilkan secara rinci pada Tabel 1. 
Tabel 1. Hasil simulasi pembebanan komponen

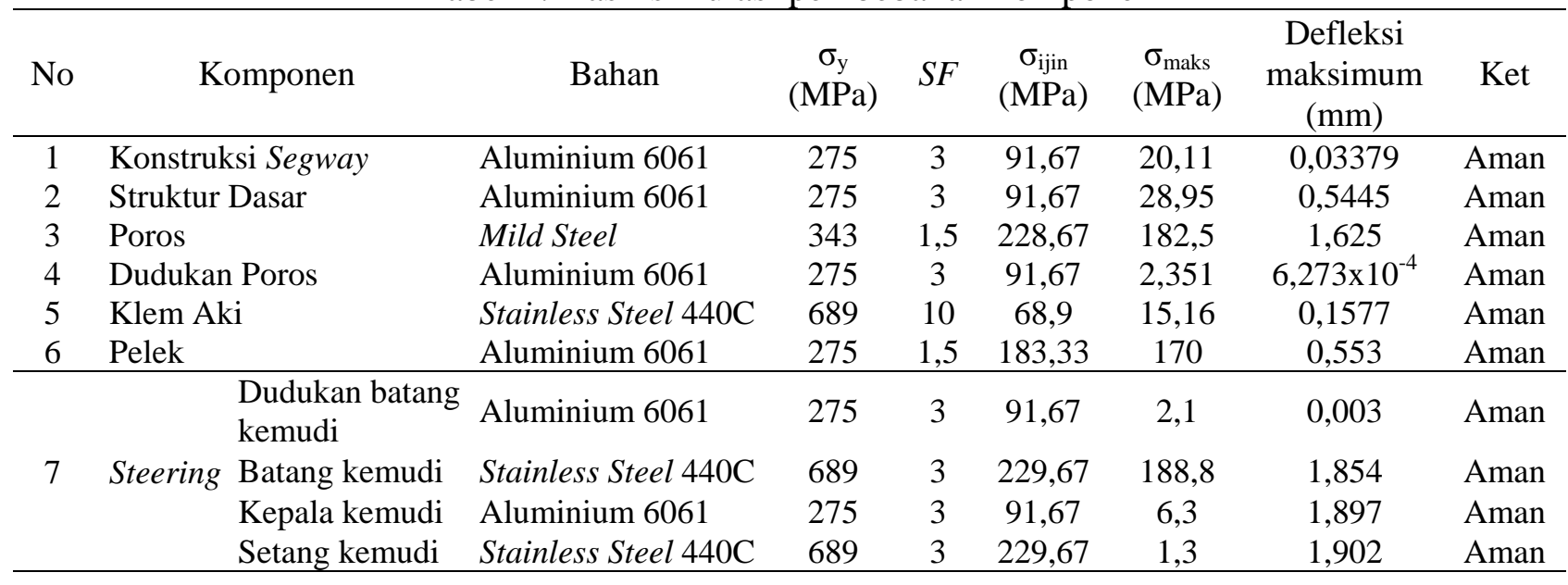

\section{KESIMPULAN}

Segway hasil perancangan memiliki dimensi p x l x t yaitu (800 x 573 x 1280) mm, digunakan untuk jarak tempuh yang pendek, dapat dikendarai oleh 1 pengemudi dengan berat badan maksimum yang disarankan adalah $80 \mathrm{~kg}$, dapat menahan beban sebesar $981 \mathrm{~N}$, dan sesuai hasil simulasi pembebanan menggunakan software menunjukkan bahwa rancangan konstruksi segway aman untuk dikendarai karena seluruh tegangan maksimum yang terjadi pada setiap komponen segway berada di bawah tegangan ijin material.

\section{DAFTAR PUSTAKA}

[1]. Ari Nugroho. Kendaraan baru yang bernama segway. http://comenkdroid.blogspot.com/ 2012/05/kendaraan-baru-yang-bernama-segway-2003.html. 13 September 2012.

[2]. Danardono Agus Sumarsono, Muhamad Agus Farhan. Stress Analysis on Chassis Structure of hybrid Vehicle Using Finite Element Method. Proceeding of 9th International Conference on Quality in Research. Universitas Indonesia. 2006.

[3]. Meadinfo. JIS S45C - Mild Steel - An Overview. http://www.meadinfo.org/2010/03/s45c-jismechanical-properties.html. 18 Oktober 2012. 